\title{
Metyrapone is an effective adjuvant treatment for major depression
}

Jahn H, Schick M, Kiefer F, et al. Metyrapone as additive treatment in major depression: a double-blind and placebo-controlled trial. Arch Gen Psychiatry 2004;61:1235-44.

\section{Does metyrapone potentiate the effects of antidepressants in people with major depression?}

METHODS

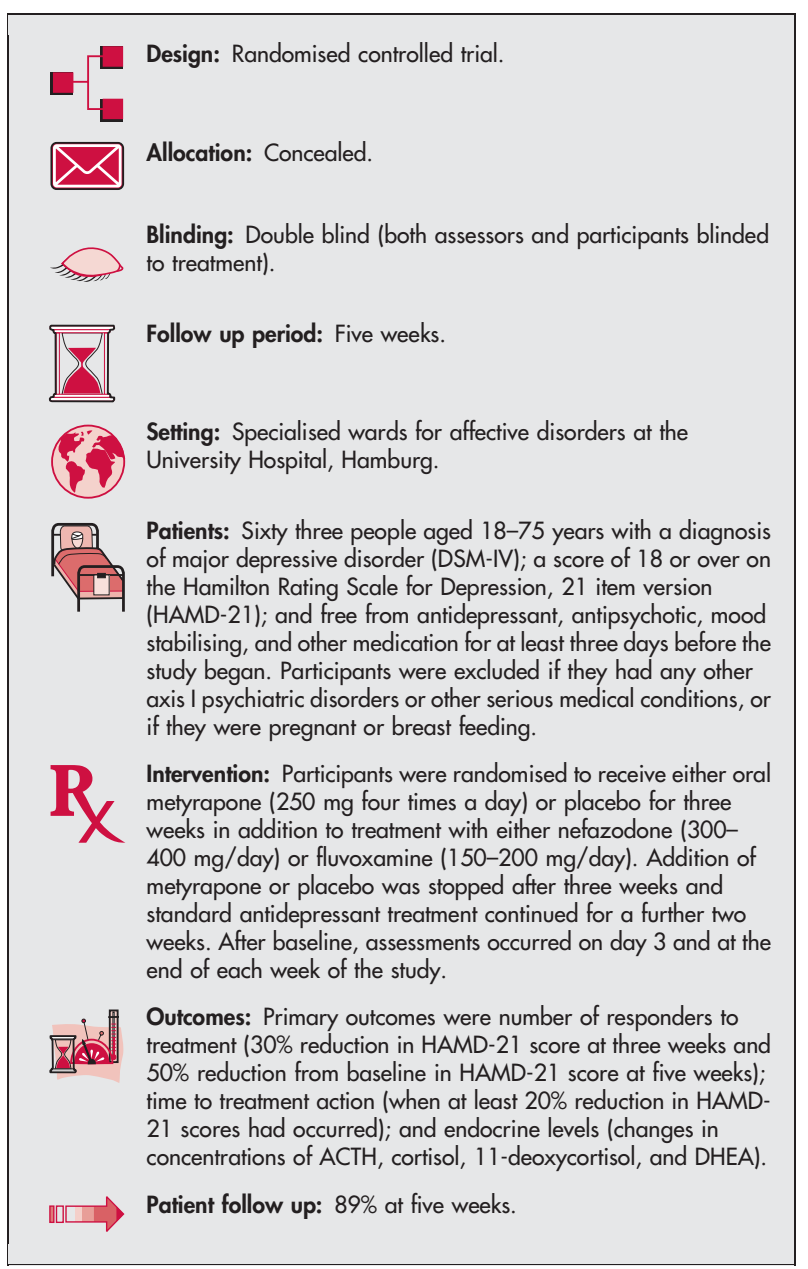

\section{MAIN RESULTS}

At both three and five weeks, significantly more people had responded to treatment in the metyrapone group compared with the placebo group $(>30 \%$ reduction in HAMD-21 at three weeks: $20 / 33(60 \%)$ with metyrapone $v 13 / 30(43 \%)$ with placebo; $\mathrm{p}=0.031$, $>50 \%$ reduction in HAMD-21 at five weeks: 10/33 (30\%) with

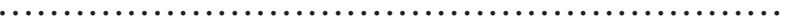
For correspondence: Holger Jahn, MD, Department of Psychiatry and Psychotherapy, University Hospital Hamburg-Eppendorf, Martinistr. 52, 20246 Hamburg, Germany; jahn@uke.uni-hamburg.de

Sources of funding: one author was supported by a fellowship from the Graduiertenkolleg 255 (Deutsche Forschungsgemeinschaft, Bonn, Germany). metyrapone $v 10 / 30(33 \%)$ with placebo; $\mathrm{p}=0.047)$. Participants taking metyrapone in addition to standard antidepressants responded to treatment faster than those taking placebo (days to $20 \%$ improvement in HAMD score by $50 \%$ of participants: seven days with metyrapone $v 14$ days with placebo; $\mathrm{p}<0.006$ ). Addition of metyrapone to antidepressant treatment lead to significantly greater plasma concentrations of ACTH, 11-deoxycortisol, and DHEA compared with addition of placebo $(\mathrm{p}<0.05)$. Cortisol concentrations were not significantly higher with metyrapone $(\mathrm{p}=0.052)$. Significantly more headaches and nausea were reported in those taking metyrapone than placebo (headaches; $\mathrm{p}=0.048$, nausea; $\mathrm{p}=0.037)$.

\section{CONCLUSIONS}

Addition of metyrapone to treatment with antidepressants improves symptoms of depression and accelerates the action of antidepressant drugs.

\section{NOTES}

Participants were stratified by sex and by antidepressant (nefazodone or fluvoxamine). Analysis of endocrine parameters was not done on an intention to treat basis.

\section{Commentary}

t is widely believed that depressive illness is often provoked and may be perpetuated by stress. Despite this our physical treatments for the disorder, all of which were discovered serendipitously, do not directly target stress hormones. The study by Jahn et al builds on the notion that drugs acting on the stress hormone system may have potential antidepressive effects in major depressive disorder. Using intention to treat analysis, a higher proportion of participants receiving metyrapone showed a positive treatment response at day 21 and at day 35 compared with those receiving placebo. Participants treated with metyrapone also showed an earlier onset of antidepressive action.

This paper is very timely and builds on advances from preclinical research, which show that stress hormones impair the ability of antidepressants to increase forebrain 5- $\mathrm{HT},{ }^{1}$ and clinical observations that suggest stress hormone antagonists may be antidepressant. ${ }^{2}$ Large scale follow up studies are required to confirm the safety and efficacy of this treatment before this approach can be adopted widely. Nevertheless, this result is encouraging to clinicians and adds to the body of work which suggests that drugs targeting the stress hormone system may be potentially helpful treatments for depression.

Allan H Young, Professor of General Psychiatry and James Newham, Research Assistant General Psychiatry Department, University of Newcastle, UK

1 Gartside SE, Leitch MM, Young AH. Altered glucocorticoid rhythm attenuates the ability of a chronic SSRI to elevate forebrain 5-HT: implications for the treatment of depression. Neuropsychopharmacology 2003; 28:1572-8.

2 Young $A H$, Gallagher P, Watson S, et al. Improvements in Neurocognitive function and mood following adjunctive treatment with mifepristone (RU486 ) in bipolar disorder. Neuropsychopharmacology 2004;29:1538-45. 